\title{
Osteogenesis Imperfecta Type IV
}

\author{
Biochemical Confirmation of Genetic Linkage to the proa2(I) Gene of Type I Collagen
}

\author{
Richard J. Wenstrup, ${ }^{*}$ Petros Tsipouras, $\neq$ and Peter H. Byers $\S$ \\ Departments of ${ }^{*}$ Pediatrics, $\S$ Medicine, and $\S$ Pathology, and $\S^{*}$ Center for Inherited Diseases, University of Washington, Seattle, \\ Washington 98195; and $\ddagger$ Departments of Biochemistry and Pediatrics, University of Medicine and Dentistry of New Jersey, Rutgers \\ Medical School, Piscataway, New Jersey 08854
}

\begin{abstract}
Fibroblasts from two affected members of a large pedigree in which osteogenesis imperfecta (OI) type IV is genetically linked to the pro 2 (I) gene of type I collagen synthesize two populations of proa2(I) chains. One population is normal; the second population appears to have a deletion of about 10 amino acid residues from the middle of the triple helical domain. The mutation in proa 2(I) causes increased posttranslational modification in the amino-terminal half of some pro $1(\mathrm{I})$ chains, lowers the melting temperature of type I collagen molecules that incorporate a mutant pro $\alpha 2$ (I) chain, and prevents or delays the secretion of those molecules from fibroblasts in cell culture. On the basis of this study and linkage studies in additional families, it appears that the OI type IV phenotype is often the result of heterozygosity for mutations in proa2(I) that alter the triple helical structure of type I collagen.
\end{abstract}

\section{Introduction}

Most forms of osteogenesis imperfecta (OI) ${ }^{1}$ are due to structural abnormalities in or decreased production of type I collagen (13 ). Studies of collagens synthesized by cultured fibroblasts from different patients with OI type I (4-6), OI type II (7-17), and OI type III (18-22) have demonstrated evidence of mutations in the pro $\alpha 1(\mathrm{I})$ and pro 2 (I) genes of type I collagen. There is less information regarding the biochemical basis of OI type IV, which differs clinically from the other relatively mild autosomal dominant OI phenotype, OI type I. Individuals with OI type IV have normal or gray rather than blue sclerae, may have mild to moderate short stature with long bone deformity, and have a far greater incidence of dentinogenesis imperfecta $(23,24)$. We have recently provided evidence of abnormal triple helical structure of type I collagen in one patient with the OI type IV phenotype (25), and Tsipouras et al. have demonstrated linkage of the OI type IV phenotype to the pros2(I) gene of type I collagen on chromosome 7 in four pedigrees (26-28).

To circumvent some of the difficulties inherent in the analysis of subtle abnormalities in a large heteropolymeric molecule such

Presented in part at the 35th annual meeting of the American Society of Human Genetics, Toronto, Canada, October 31, 1984.

Received for publication 16 December 1985 and in revised form 18 June 1986

1. Abbreviations used in this paper: DMEM, Dulbecco's modified Eagle's medium; FCS, fetal calf serum; OI, osteogenesis imperfecta; PAGE, polyacrylamide gel electrophoresis.

J. Clin. Invest.

(C) The American Society for Clinical Investigation, Inc.

0021-9738/86/12/1449/07 \$1.00

Volume 78, December 1986, 1449-1455 as type I collagen, we chose to study cell strains from individuals in a large pedigree in which there is evidence of linkage of the OI type IV phenotype to the proa2(I) gene (26). This approach enabled us to focus attention on only one class of constituent chains of type I collagen. In this report we describe studies of type I collagen synthesized by cells cultured from one unaffected and two affected members of this pedigree (26). The affected members are heterozygous for a mutation in the pro $\alpha 2$ (I) gene that produces a shortened pro $\alpha 2$ (I) chain, thus confirming linkage in this family. The deletion from the middle of the triple helical domain of $\alpha 2$ (I) causes excessive posttranslational modification of the amino-terminal half of the $\alpha$-chains in molecules that contain the shortened $\alpha 2$ (I) chains. Molecules that contain the mutant $\alpha 2$ (I) chains are selectively retained within fibroblasts. These studies provide direct evidence that mutations in $\alpha 2$ (I) are responsible for the clinical and biochemical features of $\mathrm{OI}$ type IV in this family and, in the context of additional linkage data $(27,28)$ and biochemical studies (reference 25 , Wenstrup, R. J., and P. H. Byers, unpublished observations), suggest that many individuals with OI type IV have mutations in $\alpha 2(\mathrm{I})$.

\section{Methods}

Fig. 1 shows the pedigree. Cells from one unaffected member (II-3) and two affected family members (II-5 and III-6) were studied. The details of physical findings for II-5 and III-6 are presented here and Table I summarizes the findings in all family members.

- II-5. A 41-yr-old mother of the proband III-6 who sustained eight fractures during childhood and adolescence. Her first fracture was at the age of $2 \mathrm{yr}$. The diagnosis of $\mathrm{OI}$ was established when her son was born. On physical examination her measurements were: height $153 \mathrm{~cm} \mathrm{(3 \% ),}$ weight $53.2 \mathrm{~kg}(50 \%)$, and head circumference $57.4 \mathrm{~cm}(97 \%)$. No skeletal deformity was observed. Scleral hue was white, teeth were discolored, there was radiologic evidence of dentinogenesis imperfecta, and the audiogram revealed a normal range of hearing. Patient gave a history of easy bruising.

III-6. An 8-yr-old male born with rib fractures, who subsequently sustained approximately 25 fractures. At birth he was noted to have bowed legs. On physical examination his measurements were: height $113.3 \mathrm{~cm} \mathrm{(<3 \% ),} \mathrm{weight} 22.4 \mathrm{~kg}(25 \%)$, and head circumference $53 \mathrm{~cm}$ $(>97 \%)$. An angulation deformity of the right tibia was observed but there was no scoliosis or pectus deformity. Scleral hue was white. Teeth in mixed dentition were discolored. There was radiologic evidence of dentinogenesis imperfecta and the audiogram revealed a normal range of hearing.

Dermal fibroblasts were obtained from outgrowths of skin taken from the inner aspect of the forearm of two affected and one unaffected family members (II-3, II-5, and III-6 in the pedigree). Biochemical studies were performed on cells between the fourth and twelfth passages. The cultures were maintained in Dulbecco's modified Eagle's medium (DMEM) containing 10\% fetal calf serum (FCS) (Gibco, Grand Island, NY), $100 \mathrm{U} /$ $\mathrm{ml}$ penicillin, $100 \mu \mathrm{g} / \mathrm{ml}$ streptomycin, and $2.5 \mathrm{mM}$ glutamine in a humidified atmosphere of $9 \% \mathrm{CO}_{2} /$ air at $37^{\circ} \mathrm{C}$. Control cell strains were obtained from newborn individuals who had no evidence of connective tissue disease. All samples were obtained with appropriate consent. 


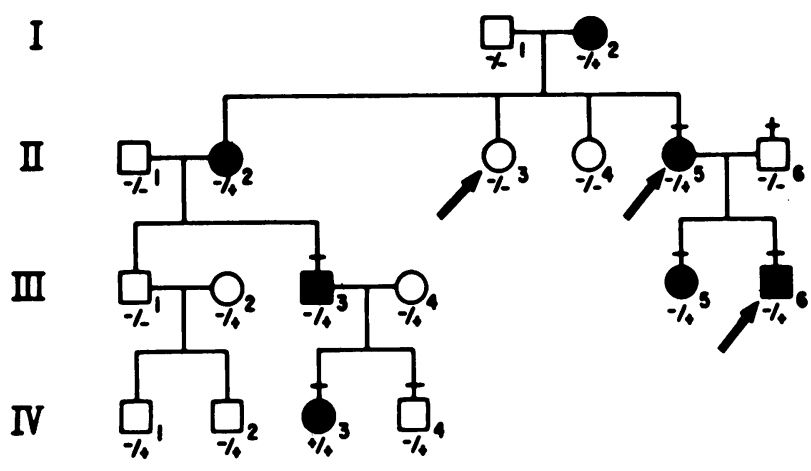

Figure 1. Family pedigree, reprinted with permission (26). Symbols: individuals heterozygous $(-1+)$ and homozygous for the absence $(-/-)$ and presence $(+/+)$ of a polymorphic EcoRI site in $\alpha 2(\mathrm{I})$; horizontal bars, individuals examined by one of us (Dr. P. Tsipouras); solid circles, solid squares, affected by OI; arrows, studied biochemically in this paper.

To label proteins for analysis of procollagens or collagens, $2.5 \times 10^{5}$ cells were plated in 35-mm culture dishes (Corning Science Products, Corning, NY) and allowed to attach and spread overnight. Unless otherwise indicated, the cells were preincubated for $4 \mathrm{~h}$ in $0.7 \mathrm{ml}$ DMEM lacking FCS and supplemented with $50 \mu \mathrm{g} / \mathrm{ml}$ ascorbic acid. The proteins were radiolabeled by addition of $\left[2,3,4,5-{ }^{3} \mathrm{H}\right]$-proline $(108 \mathrm{Ci} / \mathrm{mmol}$; Amersham Corp., Arlington Heights, IL) at concentrations of 30 to 120 $\mu \mathrm{Ci} / \mathrm{ml}$, depending on the studies planned. After $16 \mathrm{~h}$ incubation, medium and cell layer proteins were harvested separately and proteolytic enzymes were inhibited as described (7). Samples were concentrated by precipitation with $30 \%$ ethanol followed by air drying. Medium and cell layer procollagens were analyzed under reducing conditions on 5\% sodium dodecyl sulfate (SDS) polyacrylamide gels as described by Laemmli (29) except that $2 \mathrm{M}$ urea was included in the system to enhance the separation of pro $\alpha 1$ (I) from pro $\alpha 1$ (III) chains. Dried procollagens were dissolved in $60 \mu \mathrm{l}$ of sample buffer with $7.7 \mathrm{mg} / \mathrm{ml}$ dithiothreitol and boiled for 3 min to reduce disulfide bonds and denature the procollagen molecules. After electrophoresis, radioactive proteins were detected by radio-autofluorography (30) using $\mathrm{EN}^{3} \mathrm{HANCE}$ (New England Nuclear, Boston, $\mathrm{MA})$ as the fluor.

To examine ratios of newly synthesized pro $\alpha$ (I) to pro $\alpha$ (I) chains, $1.5 \times 10^{5}$ cells were plated in $35-\mathrm{mm}$ culture dishes, allowed to spread overnight, and then preincubated for $4 \mathrm{~h}$ as described above. The cells were trypsinized off the dishes into microcentrifuge tubes, pelleted at $10,000 \mathrm{rpm}$ for $5 \mathrm{~s}$, and the supernatant was removed. $30 \mu \mathrm{l}$ of the preincubation medium was added, the cells were gently resuspended, and $\left[2,3,4,5^{3} \mathrm{H}\right]$ proline was added to a concentration of $2 \mathrm{mCi} / \mathrm{ml}$ for 18 $\mathrm{min}$. Then the cells were repelleted, the medium discarded, and the cells were washed once with phosphate-buffered saline. The cells were suspended in sample buffer containing $2 \%$ SDS and $2 \mathrm{M}$ urea and boiled for $5 \mathrm{~min}$. Intracellular pro $\alpha$ chains were separated by electrophoresis in a 5\% SDS polyacrylamide gel as described above. Quantitation of radioactivity in pro $\alpha 1$ (I) and pro $\alpha$ 2(I) chains was performed by densitometry of autoradiofluorograms exposed in the linear range (31).

The ratio of type I to type III secreted collagen into culture medium during a 16-h incubation was measured by gel densitometry of fluorograms exposed in the linear range (31). The density of all the pro $\alpha, \mathrm{pC} \alpha$, $\mathrm{pN} \alpha$, and $\alpha$ chains was determined and summed for each collagen. Incorporation of $\left[{ }^{3} \mathrm{H}\right]$ proline into collagenous protein was measured by bacterial collagenase digestion as previously described (32).

To examine unmodified pro $\alpha$ chains, $2.5 \times 10^{5}$ cells were plated as above and then were preincubated for $4 \mathrm{~h}$ in $0.7 \mathrm{ml}$ DMEM that lacked FCS but contained $50 \mu \mathrm{g} / \mathrm{ml}$ of ascorbic acid and $0.5 \mathrm{mM} \alpha, \alpha^{\prime}$-dipyridyl. The cells were then incubated with $100 \mu \mathrm{Ci} / \mathrm{ml}$ of $\left[{ }^{3} \mathrm{H}\right]$ proline for $16 \mathrm{~h}$ under identical conditions. Cell layer proteins were harvested and analyzed by electrophoresis under reducing conditions as described above.

Collagens were prepared by dissolving ethanol-precipitated procollagens in $0.5 \mathrm{~N}$ acetic acid and digesting with $50 \mu \mathrm{g} / \mathrm{ml}$ pepsin (Boehringer Mannheim Diagnostics, Houston, TX) at $4^{\circ} \mathrm{C}$ for $16 \mathrm{~h}$. The reaction was terminated by adding pepstatin to $5 \mu \mathrm{g} / \mathrm{ml}$ and molecules were concentrated by lyophilization and analyzed by electrophoresis.

Fibroblast collagenase fragments of $\alpha 1(\mathrm{I})$ and $\alpha 2$ (I) chains were prepared from $\left[{ }^{3} \mathrm{H}\right]$ proline-labeled procollagens after digestion with pepsin (33). The fibroblast collagenase was a generous gift from Eugene Bauer, M.D. (Washington University, St. Louis, MO).

$\mathrm{CNBr}$ cleavage of $\alpha$-chains and of fibroblast collagenase products of $\alpha$-chains of type I collagen in gels was performed as previously described (34) except that digestion was limited to $2 \mathrm{~h}$ and the samples were subsequently washed three times with 20 vol of water for 10 min each (13). The peptides were separated on second-dimension gels as described (34).

In some experiments, collagenous proteins were cleaved sequentially by pepsin, fibroblast collagenase, and $\mathrm{CNBr}$. The collagenase fragments were cleaved with $20 \mu \mathrm{g} / \mathrm{ml} \mathrm{CNBr}$ in $70 \%$ formic acid at $30^{\circ} \mathrm{C}$ for $5 \mathrm{~h}$, lyophilized, washed in distilled $\mathrm{H}_{2} \mathrm{O}$, and lyophilized again. The peptides were separated by isoelectric focusing in a vertical slab gel using the gel composition and buffers previously described (35). After first-dimension electrophoresis, gel strips were cut out and washed in $\mathbf{3 0}$ vol of water for $20 \mathrm{~min}$ three times, then twice in $15 \mathrm{vol}$ of $30 \%$ glycerol, $0.1 \mathrm{M}$ Tris$\mathrm{HCl}(\mathrm{pH} \mathrm{6.8)}$ for $10 \mathrm{~min}$, and loaded onto a $12.5 \%$ SDS polyacrylamide gel with a 5\% stacking gel for separation of peptides in the second dimension.

Thermal denaturation temperatures of normal and abnormal collagens were determined as previously described (36).

\section{Results}

Dermal fibroblasts from two affected members of this family synthesized two populations of pro $\alpha$ 1(I) chains of type I procollagen. One population co-migrated with the corresponding pro $\alpha 1$ (I) chains synthesized by cells from the control and from

Table I. Clinical Features of Affected Examined Members of Family with OI Type IV

\begin{tabular}{|c|c|c|c|c|c|c|c|}
\hline Pedigree & Age & Fractures & Height & Skeletal deformity & $\begin{array}{l}\text { Scleral } \\
\text { hue }\end{array}$ & $\begin{array}{l}\text { Dentinogenesis } \\
\text { imperfecta }\end{array}$ & Hearing \\
\hline & $y r$ & & $\mathrm{~cm}$ & & & & \\
\hline $\mathbf{I}-2$ & 75 & None & $133(<3 \%)$ & None & White & Edentulous & Mixed loss \\
\hline II-2 & 57 & 1 & $149.5(3 \%)$ & None & White & Present & Sensorineural \\
\hline II-5 & 41 & 8 & $153(10 \%)$ & None & White & Present & Normal \\
\hline III-3 & 29 & 20 & $156.5(<3 \%)$ & None & White & Present & Not tested \\
\hline III-5 & 18 & 3 & $150.2(3 \%)$ & Angulation right elbow & White & Present & Normal \\
\hline III-6 & 8 & 25 & $113.3(<3 \%)$ & Angulation right tibia & White & Present & Normal \\
\hline IV-3 & 3 & 7 & $81.5(<3 \%)$ & None & White & Present & Normal \\
\hline
\end{tabular}


an unaffected family member. A second population, seen only in the cell layer, migrated more slowly and appeared as a broad band or doublet during electrophoresis (Fig. $2 A$ ). The slower migrating pro $\alpha$ l(I) chains were from within the cells, for when cells were removed from the matrix by trypsinization before isolating the pro $\alpha$ chains, the abnormal chains were still present (data not shown). When pro $\alpha$ chains were labeled in the presence of $\alpha, \alpha^{\prime}$-dipyridyl, which inhibits posttranslational modification of prolyl and lysyl residues, the OI cells produced only a single population of pro $\alpha 1$ (I) chains, which co-migrated with pro $\alpha 1(\mathrm{I})$ chains synthesized by control cells and those from the unaffected family member (Fig. $2 \mathrm{~B}$ ). This indicated that the apparent increase in molecular weight of the slower migrating pro $\alpha 1$ (I) chains found inside OI cells was due to increased posttranslational modification, not peptidyl insertion. To determine whether the increased posttranslational modifications involved the triple helical domain, $\alpha$-chains produced by pepsin digestion of procollagens were prepared and separated by electrophoresis (Fig. $2 C$ ). There were two populations of $\alpha 1$ (I) from the cell layer

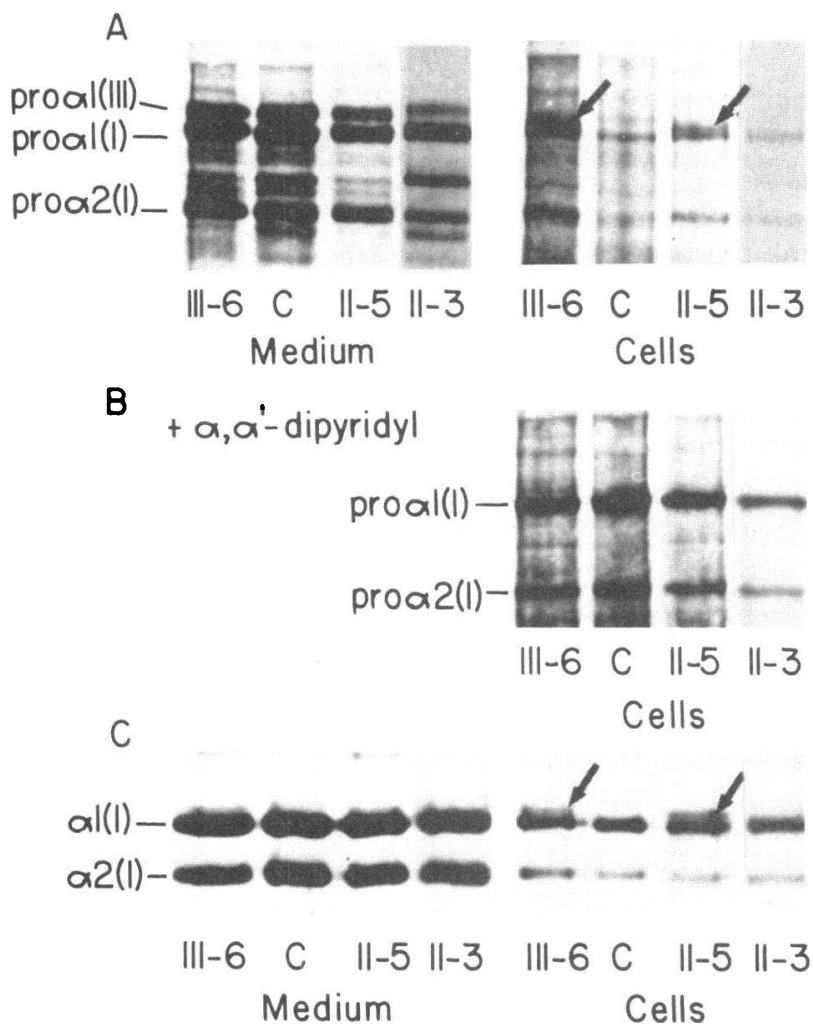

Figure 2. Autoradiofluorograms of radiolabeled procollagens after SDS PAGE $(A)$ Pro $\alpha$ chains from medium and cell layer. There was a slower migrating population of pro $\alpha 1$ (I) chains (arrows) from the cell layer of OI cell strains (II-5 and III-6) not seen in control (C) or the unaffected family member (II-3). Only normally migrating pro $\alpha$ chains appeared in medium of $\mathrm{OI}$ and control cell strains. (B) Unmodified, intracellular pro $\alpha$ chains from OI and control cell strains produced by labeling in the presence of $\alpha, \alpha^{\prime}$-dipyridyl. OI cell strains (II-5 and III-6) produced only single populations of pro $\alpha$ l(I) chains that comigrated with those of control. Fibroblasts treated with $\alpha, \alpha^{\prime}$-dipyridyl did not secrete significant amounts of procollagen into the fibroblast medium. $(C)$ Collagenous proteins after partial proteolytic digestion with pepsin to yield $\alpha$-chains. There was a slow migrating population (arrows) of $\alpha 1$ (I) in the cell layer of OI cell strains (II-5 and III-6) not seen in controls. Slow migrating $\alpha 1$ (I) chains were not seen in medium from OI fibroblasts. samples from the patients' cells but single populations from the cell layers of control and the unaffected family member cells. Medium from OI fibroblasts contained single populations of $\alpha 1$ (I) chains that co-migrated with the $\alpha 1$ (I) chains made by control cells and cells from the unaffected family member. Thus, the increased posttranslational modification of intracellular pro $\alpha 1$ (I) chains involved the triple helical domain. To determine which region of the slower migrating $\alpha 1$ (I) chains from OI cells was overmodified, $\mathrm{CNBr}$ peptides of normal and slow migrating chains were examined (Fig. 3). $\alpha$-Chains were separated in the

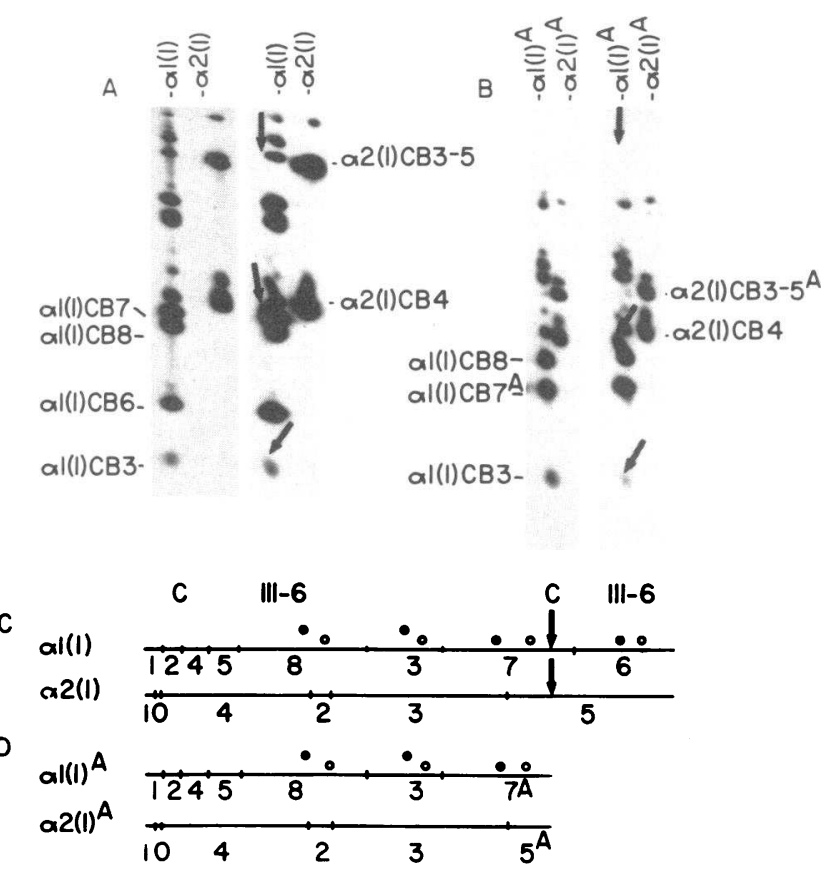

Figure 3. (A) Autoradiofluorogram of $\mathrm{CNBr}$ cleavage products of intracellular $\alpha$-chains from control (C) and OI (III-6) fibroblasts. Radiolabeled $\alpha$-chains were separated on a 5\% polyacrylamide gel, then cleaved in the gel with $\mathrm{CNBr}$ as described in Methods. The peptides were then separated in a $12.5 \%$ gel. $\alpha 1$ (I) chains from control cells and the normally migrating $\alpha 1$ (I) chains from the OI cells yielded the usual four large peptides: $\alpha 1$ (I)CB8, $\alpha 1$ (I)CB3, $\alpha 1$ (I)CB7, and $\alpha 1$ (I)CB6 (see $C$ ), as well as partial cleavage products. Slow migrating $\alpha$-chains from OI cells (arrow at top of autoradiofluorogram) yielded $\alpha 1$ (I)CB6, a peptide that migrated more slowly than $\alpha 1$ (I)CB3 (arrow), a single spot in the region of $\alpha 1$ (I)CB7 (arrow), and partial cleavage products. (B) Autoradiofluorogram of $\mathrm{CNBr}$ peptides of $\alpha 1(\mathrm{I})^{\mathrm{A}}$ and $\alpha 2(\mathrm{I})^{\wedge}$. Radiolabeled $\alpha 1(\mathrm{I})^{\wedge}$ and $\alpha 2(\mathrm{I})^{\wedge}$ fragments generated by fibroblast collagenase cleavage of $\alpha$-chains of type I collagen (see Methods) were separated in an $8 \%$ polyacrylamide gel, cleaved in the gel with $\mathrm{CNBr}$, and the resulting peptides were separated in a $12.5 \%$ gel. $\alpha 1(\mathrm{I})^{\wedge}$ fragments from control cells and the normally migrating $\alpha 1(\mathrm{I})^{\wedge}$ fragments from the $O I$ cells yielded the expected three large peptides: $\alpha 1(\mathrm{I}) \mathrm{CB} 8, \alpha 1(\mathrm{I}) \mathrm{CB} 3$, and $\alpha 1(\mathrm{I}) \mathrm{CB} 7^{\mathrm{A}}$ (see $D$ ), as well as partial cleavage products. Slow migrating $\alpha 1(\mathrm{I})^{\mathrm{A}}$ fragments from OI cells (arrow at top of autoradiofluorogram) yielded $\alpha 1(\mathrm{I}) \mathrm{CB} 7^{\mathrm{A}}$, a peptide that migrated slower than $\alpha 1$ (I)CB3 (arrow), a peptide that migrated slower than $\alpha 1$ (I)CB8 (arrow), and partial cleavage products. (C) Diagram representing the arrangement of $\mathrm{CNBr}$ peptides in $\alpha 1(\mathrm{I})$ and $\alpha 2(\mathrm{I})$. The arrows in the diagram represent the fibroblast collagenase cleavage sites, and the circles represent the relative mobilities of the normal (open circles) and overmodified (solid circles) peptides. $\mathrm{CNBr}$ does not cleave efficiently at the methionine between $\alpha 2$ (I)CB3 and $\alpha 2$ (I)CB5. (D) Diagram representing the arrangement of $\mathrm{CNBr}$ peptides in $\alpha 1(\mathrm{I})^{\wedge}$ and $\alpha 2(\mathrm{I})^{\mathrm{A}}$. The circles represent the relative mobilities of the normal (open circles) and overmodified (solid circles) peptides. 
first dimension by SDS polyacrylamide gel electrophoresis (PAGE) (see Methods), gel strips containing $\alpha$-chains were cut out, chains were cleaved in the gel at methionyl residues by $\mathrm{CNBr}$, and the resultant peptides were separated by gel electrophoresis in the second dimension. $\mathrm{CNBr}$ peptides of $\alpha$-chains from the medium of $\mathrm{OI}$ fibroblasts were indistinguishable from control (data not shown). Intracellular $\alpha 1$ (I) chains from control cells and the normally migrating population of intracellular chains from OI cells yielded the expected four large peptides (Fig. 3 A): $\alpha 1$ (I)CB8, $\alpha 1$ (I)CB3, $\alpha 1$ (I)CB7, and $\alpha 1$ (I)CB6. The slower migrating population of intracellular $\alpha 1(\mathrm{I})$ chains from OI cells yielded a peptide that migrated slower than $\alpha 1$ (I)CB3, a normally migrating $\alpha(\mathrm{I}) \mathrm{CB} 6$, and a peptide that co-migrated with $\alpha$ 1(I)CB7. Because we thought that the spot corresponding to the $\alpha 1$ (I)CB7 peptide from the slower migrating $\alpha 1$ (I) chains might also contain slower migrating $\alpha 1$ (I)CB8 peptides, $\mathrm{CNBr}$ peptide maps were made from the $A$ fragments generated by fibroblast collagenase, which cleaves $\alpha 1$ (I) and $\alpha 2$ (I) asymmetrically (see arrows, Fig. $3 C$ ). Cleavage of $\alpha 1$ (I) at the collagenase site near the carboxyl end of $\alpha 1$ (I)CB7 followed by $\mathrm{CNBr}$ cleavage results in a shortened fragment, $\alpha 1(\mathrm{I}) C B 7^{A}$, that is easily separated from $\alpha 1$ (I)CB8. When A fragments of type I collagen retained within OI cells were separated by SDS PAGE and then cleaved with $\mathrm{CNBr}$ (Fig. $3 \mathrm{~B}$ ), the slower migrating $\alpha 1(\mathrm{I})^{\mathrm{A}}$ fragment produced a peptide that migrated more slowly than $\alpha 1$ (I)CB3, a normally migrating $\alpha 1$ (I)CB7 $7^{\mathrm{A}}$, and a peptide that migrated more slowly than $\alpha$ l(I)CB8. Thus, the slower migrating population of $\alpha 1$ (I) was overmodified amino-terminal to the $\alpha 1$ (I)CB7 domain.

These findings contained an apparent paradox: although the genetic linkage data (26) indicated that the mutation should be in an $\alpha 2$ (I) chain, the evident structural abnormality in type I collagen was overmodification of the amino-terminal half of some intracellular $\alpha 1$ (I) chains produced by the OI cells. Because
Steinmann et al. (12) have demonstrated that a mutation of $\alpha 1(\mathrm{I})$ could cause overmodification in all three constituent $\alpha$ chains in a molecule at residues amino-terminal to the mutation, we hypothesized that a mutation in the middle of an $\alpha 2(\mathrm{I})$ chain might also cause excessive posttranslational modification aminoterminal to its location in all chains in such a molecule but that because $\alpha 2(\mathrm{I})$ normally is more modified than $\alpha 1$ (I), overmodification in $\alpha 2$ (I) might be more difficult to detect. Because overmodification of abnormal molecules involved only the aminoterminal half of the triple helical domain, we examined the region in the middle of the triple helical domain of $\alpha 2(\mathrm{I})$ in more detail. Because the methionyl residue between $\alpha 2$ (I)CB3 and $\alpha 2$ (I)CB5 is inefficiently cleaved by $\mathrm{CNBr}, \alpha$-chains were cleaved with fibroblast collagenase and then cleaved with $\mathrm{CNBr}$ (see diagram, Fig. $3 C$, for relative locations of $\mathrm{CNBr}$ and fibroblast cleavage sites). Peptides cleaved in this way were separated first by isoelectric focusing in a 5\% polyacrylamide gel, then gel strips were placed over a $12.5 \%$ SDS polyacrylamide gel and peptides were separated by molecular weight in a second dimension (Fig. 4). Although each peptide was heterogeneous with respect to charge as has been reported elsewhere $(35,37)$, the cell layer samples of the OI cell strains (Fig. $4 B$, and lower right, $C$ ) contained two major populations of $\alpha 2$ (I)CB3-5 ${ }^{A}$. One population was in normal position, and a second population migrated further (vertically) into the second-dimension gel and had a more acidic isoelectric point (shifted leftward in the figure). This second population of $\alpha 2$ (I)CB3-5 $5^{A}$ was not present in collagens secreted by $\mathrm{OI}$ cells or in the cell layer or secreted collagens of control cells or those from the unaffected family member. These findings are consistent with a small deletion, of about 10 residues, in the $\alpha 2$ (I)CB3-5 $5^{A}$ peptide that involves the net loss of at least one basic residue. Because we did not observe the shortened $\alpha 2(\mathrm{I})$ fragment in the medium, we determined whether the shortened $\alpha 2(\mathrm{I})$ chain affected the thermal stability of type I collagen mol-

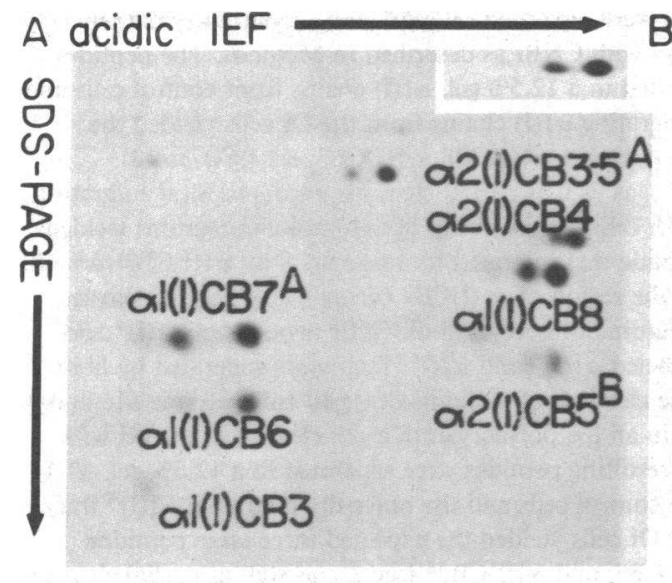

Control

Figure 4. Autoradiofluorograms of two-dimensional maps of peptides generated by cleavage with fibroblast collagenase and $\mathrm{CNBr}$ from collagens from control (C) and OI (III-6) cells. Peptides were separated first by isoelectric focusing in a $5 \%$ polyacrylamide gel, then separated by molecular weight in a $12.5 \%$ SDS polyacrylamide gel in the second dimension. The methionine between $\alpha 2$ (I)CB3 and $\alpha 2$ (I)CB5 is ineffciently cleaved by $\mathrm{CNBr}$. All peptides usually show charge heterogeneity. In $B$, which shows peptides generated from intracellular collagens from III-6, there was a second, abnormal population of $\alpha 1$ (I)CB3-5^ which appeared shortened and was more acidic than normal (arrows).

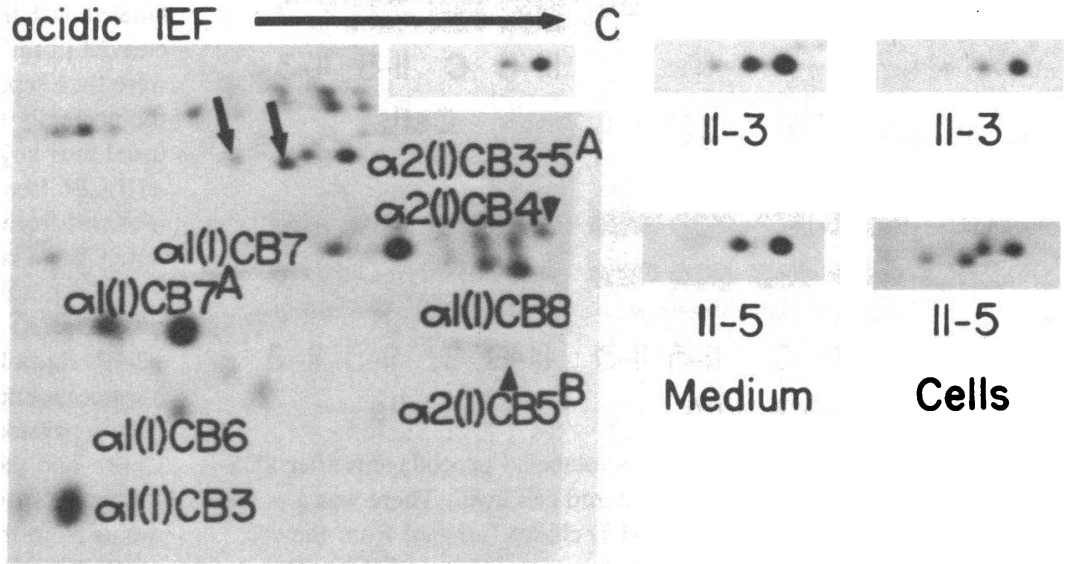

III-6

Other peptides from III- 6 were normal except for evidence of overmodification of some $\alpha 1$ (I)CB8 and $\alpha 1$ (I)CB3 peptides. The abnormal population of $\alpha 2$ (I)CB3- $5^{\wedge}$ was not seen in fibroblast medium from III-6 (inset at top right, $B$ ), in the cell layer or medium from control ( $A$ and inset in $A$ ), or unaffected family member (II-3, $C$ ), or in medium from the other affected family member (II-5, $C$ ). It was seen in the cell layer of II-5, however $(C)$. The diagram at the bottom of Fig. 3 shows the relative sizes and positions of $\mathrm{CNBr}$ peptides and fibroblast collagenase cleavage sites in the triple helical domain of type I collagen. 


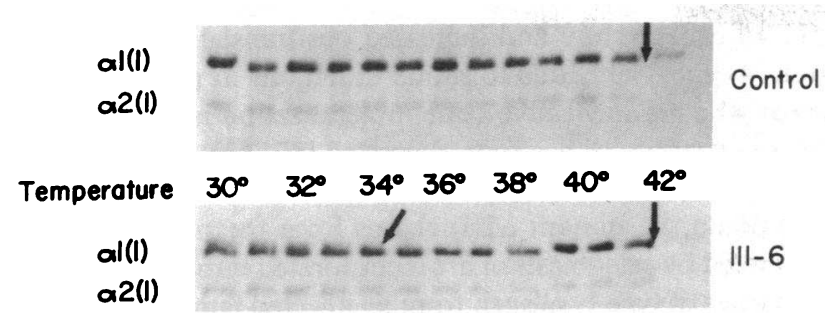

Figure 5. Autoradiofluorogram showing melting temperatures of intracellular type I collagen molecules from control (C) and OI (III-6) fibroblasts. Pepsin-digested samples were gradually warmed from $30^{\circ}$ to $43^{\circ} \mathrm{C}$ at the rate of $1^{\circ} \mathrm{C} / 12 \mathrm{~min}$, and samples were removed at $1.0^{\circ} \mathrm{C}$ intervals, rapidly cooled to $20^{\circ} \mathrm{C}$, and then digested with trypsin for 2 min. After trypsin digestion, samples were separated on a 5\% SDS polyacrylamide gel. Molecules containing overmodified $\alpha 1$ (I) chains from OI cells were digested at $\sim 35^{\circ} \mathrm{C}$ (slanted arrow) as compared with normally migrating type I collagen molecules (vertical arrows) and type I collagen molecules from control cells, which became protease sensitive at $42^{\circ} \mathrm{C}$.

ecules that contained them (Fig. 5). Type I collagen from each OI cell strain had a biphasic curve: molecules that contained overmodified $\alpha 1$ (I) chains (presumably a marker for molecules containing a mutant $\alpha 2[\mathrm{I}]$ chain) melted at $35^{\circ} \mathrm{C}$, as compared with molecules that contained normally migrating $\alpha 1$ (I) and $\alpha 2$ (I) chains from $\mathrm{OI}$ and control cells, which melted at $42^{\circ} \mathrm{C}$.

To determine whether the decreased triple helical stability of some type I procollagen molecules resulted in reduced secretion into fibroblast medium, we measured the ratios of type I to type III collagen chains in fibroblast medium after a 16-h incubation with $\left[{ }^{3} \mathrm{H}\right]$ proline. Type I collagen/type III collagen ratios were 3.14 (II-5) and 3.85 (II-6) for OI cell strains compared with 3.58 for control. Quantitation of collagen production by bacterial collagenase assay (29) (Table II) demonstrated that for OI cells, $22 \%$ (II-5) and $33 \%$ (III-6) of incorporated $\left[{ }^{3} \mathrm{H}\right]$ proline was in collagenous protein compared with $25 \%$ for control. Finally, to determine whether the mutation in proa2(I) altered the rate of production of proa2(I) chains, ratios of newly synthesized pro $\alpha 1$ (I) to pro $\alpha 2$ (I) chains were determined. The ratio of pro $\alpha 1$ (I) to pro $\alpha 2(\mathrm{I})$ was 2.12 for one OI cell strain (II-5) and was 2.02 for control.

\section{Discussion}

Cultured dermal fibroblasts from two affected members of a large family in which OI type IV is linked to the proa2(I) gene synthesize two populations of pro $\alpha 2(I)$ chains. One population is normal and is present in both medium and cell layer samples. A second population, found only within the cells, is shortened by about 10 amino acid residues and the $\mathrm{CNBr}$ peptide fragment containing the apparent deletion has a more acidic isoelectric point than the normal peptide. The effect of the mutation is to cause increased posttranslational modification of the amino-terminal half of some intracellular $\alpha 1$ (I) chains, presumably those $\alpha 1(\mathrm{I})$ chains that are incorporated into molecules that also contain the shortened $\alpha 2$ (I) chain. The melting temperature of type I collagen molecules that contain the mutant chain is $35^{\circ} \mathrm{C}$, as compared with $42^{\circ} \mathrm{C}$ for type I collagen molecules that contain normally migrating chains; the abnormal molecules are either selectively retained within fibroblasts or very rapidly degraded after secretion under standard labeling conditions in tissue culture. The presence of the shortened $\alpha 2(I)$ chains in the OI cells confirms that in this family, the $(+)$ allele at the polymorphic EcoRI site in the pro $\alpha 2(\mathrm{I})$ gene on chromosome 7 contains a mutation that is responsible for the OI type IV phenotype.

Presence of overmodified proa 1(I) chains in molecules with a mutation in $\alpha 2(\mathrm{I})$ requires explanation. The three most likely possibilities are: first, that the patients are genetic compounds, heterozygous for a mutation in both proa 1(I) and pro $\alpha 2(\mathrm{I})$; second, that there is a generalized abnormality in the activity or availability of collagen-modifying enzymes (prolyl and lysyl hydroxylases, and glucosyl and galactosyl transferases); and third, that abnormal triple helical formation resulting from a mutation in a single mutant chain can cause overmodification of wildtype pro $\alpha$ chains that are contained within the same molecule. We think that genetic and biochemical evidence favors the third explanation. The first explanation, that the affected family members are heterozygotes for mutations in both pro $\alpha 1(\mathrm{I})$ and pro $\alpha 2(\mathrm{I})$, can be discarded because the OI type IV phenotype in this pedigree is inherited in an autosomal dominant fashion and the genes for pro $\alpha 1(\mathrm{I})$ and pro $\alpha 2(\mathrm{I})$ are unlinked $(38,39)$. The second possibility, that there is a generalized, abnormal increase in the activity of one or more of the modifying enzymes is untenable because $(a)$ only some pro $\alpha 1(\mathrm{I})$ chains are overmodified, (b) overmodification occurs only in the amino-terminal half of the triple helical domain in affected chains, and (c) type III collagen, which is modified by the same enzymes, is not overmodified. The most likely explanation for overmodified proal(I) chains is that the mutation in $\alpha 2(\mathrm{I})$ disrupts triple helix formation. A review of the requirements for normal triple helical structure provides understanding of how a mutation in one chain

Table II. Incorporation of $\left[{ }^{3} \mathrm{H}\right]$ proline into Total and Collagenous Protein by Control and Osteogenesis Imperfecta Cells in Culture

\begin{tabular}{|c|c|c|c|c|c|}
\hline Cell strain & & Total protein & Collagen & Cpm in collagen & Collagen in medium \\
\hline & & $\mathrm{cpm} \times 10^{-3} / 2.5 \times 10^{5} \mathrm{cells}$ & $\mathrm{cpm} \times 10^{-3} / 2.5 \times 10^{5} \mathrm{cells}$ & $\%$ & $\%$ \\
\hline \multirow[t]{3}{*}{ Control } & Medium & 158.0 & 69.0 & 43.6 & \\
\hline & Cells & 154.7 & 7.7 & 4.9 & \\
\hline & Total & 312.7 & 76.7 & 24.5 & 90 \\
\hline \multirow[t]{3}{*}{ III-6 } & Medium & 142.7 & 53.3 & 37.3 & \\
\hline & Cells & 115.8 & 4.9 & 4.2 & \\
\hline & Total & 258.5 & 58.2 & 22.5 & 91.5 \\
\hline \multirow[t]{3}{*}{ II-5 } & Medium & 153.2 & 66.4 & 37.3 & \\
\hline & Cells & 106.7 & 17.2 & 16.0 & \\
\hline & Total & 259.9 & 83.6 & 32.2 & 80 \\
\hline
\end{tabular}


may produce overmodification of the mutant and wild-type chains within the same molecule, as well as decreased triple helical stability. Triple helix formation depends on having glycyl residues in every third position $(\mathrm{Gly}-\mathrm{X}-\mathrm{Y})_{\mathrm{n}}$ and the structure is stabilized by an abundance of $\mathrm{Y}$-positioned hydroxyprolyl residues. Hydroxyproline within the triple helix is formed by enzymatic hydroxylation of proline, which together with hydroxylation of certain lysyl residues, occurs as a modification of newly translated pro $\alpha$ chains. Triple helix formation is initiated at the carboxyl end and proceeds toward the amino-terminal end, and once a stable triple helix is formed, further modification is inhibited (40). We think that the mutation in the middle of the triple helical domain of pro $\alpha 2(\mathrm{I})$ in cells from this family disrupts triple helical propagation and the unwound chains amino-terminal to the mutation are available for additional modifications.

We do not know whether the deletion in $\alpha 2(\mathrm{I})$ reported here disrupts the (Gly-X-Y) sequence. Data from another OI cell strain demonstrate that decreased triple helix stability and increased posttranslational modification can result from a mutation in the chains of type I collagen that disrupts the triplet sequence. In that cell strain, which is from an infant with lethal OI type II, a single base change produces a Gly to Cys substitution in $\alpha 1$ (I)CB6, which results in a lowered melting temperature in abnormal molecules as well as overmodification of all the constituent chains $(12,17)$. However, evidence from another lethal OI cell strain suggests that a deletion within the triple helical domain may produce similar effects even if the (Gly-X-Y) $)_{n}$ sequence is preserved. That cell strain was heterozygous for an intron-to-intron deletion of three exons, with preservation of $(\mathrm{Gly}-\mathrm{X}-\mathrm{Y})_{\mathrm{n}}$ in the shortened chain. The melting temperature of molecules that contained the abnormal allelic product was lower than normal and in those molecules there was overmodification of the amino-terminal region of $\alpha 1$ (I) $(7,8,10,11$; Bonadio, J. F., and P. H. Byers, unpublished observations).

Failure to detect overmodified pro 2 (I) chains in the cell strains described in the present report may reflect the fact that pro $\alpha 2(\mathrm{I})$ is normally modified to a greater extent than pro $\alpha 1(\mathrm{I})$ (16), so that there may be few additional sites in the aminoterminal half of $\alpha 2$ (I) chains available for further modification. Further, failure to detect the shortened unmodified proa2(I) probably reflects limitations of resolution (Fig. 2 B). This OI cell strain provides additional support for the concept that overmodification of chains of type I collagen is common in cells from patients with certain forms of OI, that the extent of overmodification helps to locate a domain that contains a mutation, and that the abnormal structure contributes to the pathophysiology of the disease $(1,12,13,15,25)$.

OI type IV is a mild to moderately severe phenotype characterized by white or grey sclerae, bone fragility, moderate short stature with frequent deformity, a high incidence of dentinogenesis imperfecta, and autosomal dominant inheritance. Based on the biochemical findings in this report, which confirm genetic linkage of OI type IV to the proo2(I) locus in this family, and on linkage studies on other OI type IV families $(27,28)$, it now appears that the clinical distinction between OI type I and OI type IV is the result of different mutations in the genes of type I collagen, which in turn have differing effects on the amount and quality of bone matrix. In classic OI type I, there is simply a decrease in the amount of type I collagen produced by dermal fibroblasts $(1,4,6)$ (though the molecular causes will undoubtedly prove to be heterogeneous), but in most cases of OI type IV there is a subpopulation of type I collagen molecules with altered triple helical structure and increased posttranslational modification (41), probably due to subtle mutations in proa2(I). It is unclear whether ineffective bone mineralization is the result of overmodification, as has been suggested $(42,43)$, or whether it is due to the mutation itself. We are uncertain whether molecules that contain the mutant $\alpha 2$ (I) chains from the present family are secreted by osteoblasts or are incorporated into bony matrix. An analysis of type I collagen from an affected family member's bone would be very useful if such tissue becomes available for study. That OI fibroblasts from this family do not accumulate significant amounts of abnormal molecules in the culture medium even during very long labeling periods (data not shown) may account for the mild clinical phenotype. The OI cells also, surprisingly, secrete approximately normal amounts of type I collagen. Though we do not yet understand the mechanism for this, it may be another factor by which the severity of the clinical phenotype is modified.

\section{Acknowledgments}

We thank Dr. Judith G. Hall for obtaining a skin biopsy from two members of the family, Dr. Stephanie Schwartz for the dental evaluations, and Ms. Marsha Gardner for audiometry.

This work was supported in part by grants from the National Institutes of Health (AM-21557 and AM-15253) and by Clinical Research Grants to Peter H. Byers (6-298) and to Petros Tsipouras (6-411) from the March of Dimes Birth Defects Foundation. Peter H. Byers was an Established Investigator of the American Heart Association during a portion of this study. Petros Tsipouras is the recipient of a Clinical Investigator Award (AM-01224) from the National Institutes of Health.

\section{References}

1. Byers, P. H., and J. F. Bonadio. 1985. The molecular basis of clinical heterogeneity in osteogenesis imperfecta: mutations in type I collagen genes have different effects on collagen processing. In Genetic and Metabolic Diseases in Pediatrics. J. Lloyd and C. R. Scriver, editors. Butterworths, London. 56-90.

2. Prockop, D. J., and K. Kivirikko. 1984. Heritable diseases of collagen. N. Engl. J. Med. 311:376-386.

3. Hollister, D. W., P. H. Byers, and K. A. Holbrook. 1982. Genetic disorders of collagen metabolism. Adv. Hum. Genet. 12:1-87.

4. Barsh, G. S., K. E. David, and P. H. Byers. 1982. Type I osteogenesis imperfecta: a nonfunctional allele for pro $\alpha 1$ (I) chains of type I procollagen. Proc. Natl. Acad. Sci. USA. 79:3838-3842.

5. Byers, P. H., J. R. Shapiro, D. W. Rowe, K. E. David, and K. A. Holbrook. 1983. Abnormal $\alpha 2$-chain in type I collagen from a patient with a form of osteogenesis imperfecta. J. Clin. Invest. 71:689-697.

6. Rowe, D. W., J. R. Shaprio, M. Poirier, and S. Schlesinger. 1985. Diminished type I collagen synthesis and reduced alphal(I) collagen messenger RNA in cultured fibroblasts from patients with dominantly inherited (type I) osteogenesis imperfecta. J. Clin. Invest. 76:604-611.

7. Barsh, G. S., and P. H. Byers. 1981. Reduced secretion of a structurally abnormal type I collagen in a form of osteogenesis imperfecta. Proc. Natl. Acad. Sci. USA. 78:5142-5146.

8. Williams, C. J., and D. J. Prockop. 1983. Synthesis and processing of a type I procollagen containing shortened proal(I) chains from a patient with osteogenesis imperfecta. J. Biol. Chem. 258:5915-5921.

9. Chu, M. L., C. J. Williams, G. Pepe, J. L. Hirsch, D. J. Prockop, and F. Ramirez. 1983. Internal deletion in a collagen gene in a perinatal lethal form of osteogenesis imperfecta. Nature (Lond.). 304:78-80.

10. Barsh, G. S., C. L. Roush, J. Bonadio, P. H. Byers, and R. E. Gelinas. 1985. Intron mediated recombination causes an $\alpha 1$ (I) collagen deletion in a lethal form of osteogenesis imperfecta. Proc. Natl. Acad. Sci. USA. 82:2870-2874.

11. Chu, M.-L., V. Gargiulo, C. J. Williams, and F. Ramirez. 1985. 
Multiexon deletion in an osteogenesis imperfecta variant with increased type III collagen mRNA. J. Biol. Chem. 260:691-694.

12. Steinmann, B., V. H. Rao, A. Vogel, P. Bruckner, R. Gitzelmann, and P. H. Byers. 1984. Cysteine in the triple helical domain of one allelic product of the $\alpha 1$ (I) gene of type I collagen produces a lethal form of osteogenesis imperfecta. J. Biol. Chem. 259:11129-11138.

13. Bonadio, J. F., K. A. Holbrook, R. E. Gelinas, J. Jacob, and P. H. Byers. 1985. Altered triple helical structure of type I procollagen in lethal perinatal osteogenesis imperfecta. J. Biol. Chem. 260:17341742.

14. deWet, W. J., T. Pihlajaniemi, J. L. Myers, and D. J. Prockop. 1983. Synthesis of a shortened proa2(I) chain and decreased synthesis of pro $\alpha 2(\mathrm{I})$ chains in a proband with osteogenesis imperfecta. J. Biol. Chem. 258:7721-7728.

15. Bonadio, J., and P. H. Byers. 1985. Subtle structural alterations in the chains of type I procollagen produce osteogenesis imperfecta type II. Nature (Lond.). 316:363-366.

16. Bateman, J. F., T. Mascara, D. Chen, and W. G. Cole. 1984. Abnormal type I collagen metabolism by cultured fibroblasts in lethal perinatal osteogenesis imperfecta. Biochem. J. 217:103-115.

17. Cohn, D. H., P. H. Byers, B. Steinmann, and R. E. Gelinas. 1986. Lethal osteogenesis imperfecta resulting from a single nucleotide change. Proc. Natl. Acad. Sci. USA. 83:6045-6047.

18. Peltonen, L., A. Palotie, T. Hayashi, and D. J. Prockop. 1980. Thermal stability of type I and type III procollagens from normal human fibroblasts and from a patient with osteogenesis imperfecta. Proc. Natl. Acad. Sci. USA. 77:162-166.

19. Peltonen, L., A. Palotie, and D. J. Prockop. 1980. A defect in the structure of type I procollagen in a patient who had osteogenesis imperfecta: excess mannose in the $\mathrm{COOH}$-terminal peptide. Proc. Natl. Acad. Sci. USA. 77:6179-6183.

20. Deak, S. B., A. Nicholls, F. M. Pope, and D. J. Prockop. 1983. The molecular defect in a nonlethal variant of osteogenesis imperfecta. Synthesis of pro 2 (I) chains which are not incorporated into trimers of type I procollagen. J. Biol. Chem. 258:15192-15197.

21. Dickson, L. A., T. Pihlajaniemi, S. Deak, F. M. Pope, A. Nicholls, D. J. Prockop, and J. Myers. 1984. Nuclease S1 mapping of a homozygous mutation in the carboxyl-propeptide-coding regions of the pro $\alpha 2$ (I) collagen gene in a patient with osteogenesis imperfecta. Proc. Natl. Acad. Sci. USA. 81:4524-4528.

22. Pihlajaniemi, T., L. A. Dickson, F. M. Pope, V. R. Korhonen, A. Nicholls, D. J. Prockop, and J. C. Myers. 1984. Osteogenesis imperfecta: cloning of a pro $\alpha 2$ (I) collagen gene with a frameshift mutation. $J$. Biol. Chem. 259:12941-12944.

23. Sillence, D. O., A. Senn, and D. M. Danks. 1979. Genetic heterogeneity of osteogenesis imperfecta. J. Med. Genet. 16:101-116.

24. Paterson, C. R., S. McAllian, and R. Miller. 1982. Osteogenesis imperfecta with dominant inheritance and normal sclerae. J. Bone Jt. Surg. Am. Vol. 6:35-39.

25. Wenstrup, R. J., A. Hunter, and P. H. Byers. 1986. Osteogenesis imperfecta type IV: evidence of abnormal triple helical structure of type I collagen. Hum. Genet. 74:47-53.

26. Tsipouras, P., J. C. Myers, F. Ramirez, and D. J. Prockop. 1983. Restriction fragment length polymorphism associated with the proa2(I) gene of human type I procollagen. Application to a family with an autosomal dominant form of osteogenesis imperfecta. J. Clin. Invest. 72: 1262-1267.
27. Tsipouras, P., A.-L. Borrelsen, L. A. Dickson, K. Berg, D. J. Prockop, and F. Ramirez. 1984. Molecular heterogeneity in the mild dominant forms of osteogenesis imperfecta. Am. J. Hum. Genet. 36: 1172-1179.

28. Falk, C. T., R. C. Schwartz, F. Ramirez, and P. Tsipouras. 1986 Use of molecular haplotypes specific for the human proa2(I) collagen gene in linkage analysis of the mild autosomal dominant form of osteogenesis imperfecta. Am. J. Hum. Genet. 38:269-279.

29. Laemmli, U. K. 1970. Cleavage of structural proteins during the assembly of the head of the bacteriophage $\mathrm{T}_{4}$. Nature (Lond.). 227:680685.

30. Bonner, W. M., and R. A. Laskey. 1974. A film detection method for tritium labeled proteins and nucleic acids in polyacrylamide gels. Eur. J. Biochem. 46:83-88.

31. Laskey, R. A., and A. D. Mills. 1975. Quantitative film detection of ${ }^{3} \mathrm{H}$ and ${ }^{14} \mathrm{C}$ in polyacrylamide gels by fluorography. Eur. J. Biochem. 56:335-341.

32. Peterkofsky, B., and R. Diegelmann. 1971. Use of a mixture of proteinase free collagenases for the specific assay of radioactive collagens in the presence of other proteins. Biochemistry. 10:988-994.

33. Stricklin, G. P., A. Z. Eisen, E. A. Bauer, and J. J. Jeffrey. 1978. Human skin fibroblast collagenase: chemical properties of precursor and active forms. Biochemistry. 17:2331-2337.

34. Barsh, G. S., K. E. Peterson, and P. H. Byers. 1981. Peptide mapping of collagen chains using $\mathrm{CNBr}$ cleavage of proteins within polyacrylamide gels. Collagen Relat. Res. 1:543-548.

35. Cole, W. G., and D. Chan. 1981. Analysis of the heterogeneity of human collagens by two dimensional polyacrylamide-gel electrophoresis. Biochem. J. 197:377-383.

36. Bruckner, P., and D. J. Prockop. 1981. Proteolytic enzyme as probes for the triple helical conformation of collagen. Anal. Biochem. 110:360-368.

37. Benya, P. 1981. Two-dimensional CNBr peptide patterns of collagen types I, II, and III. Collagen Relat. Res. 1:17-26.

38. Junien, C., D. Weil, J. C. Myers, N. Van Cong, M.-L. Chu, C. Foubert, M.-S. Gross, D. J. Prockop, J.-C. Kaplan, and F. Ramirez. 1982. Assignment of the human pro $\alpha 2$ (I) collagen structural gene (COLIA2) to chromosome 7 by molecular hybridization. Am. J. Hum. Genet. 34:381-387.

39. Huerre, C., C. Junien, D. Weil, M.-L. Chu, M. Morabito, N. Van Cong, J. C. Myers, C. Foubert, M.-S. Gross, D. J. Prockop, A. Boué, J. C. Kaplan, A. de la Chappelle, and F. Ramirez. 1982. Human type I procollagen genes are located on different chromosomes. Proc. Natl. Acad. Sci. USA. 79:6627-6630.

40. Berg, R. A., and D. J. Prockop. 1973. The thermal transition of a nonhydroxylated form of collagen. Evidence for a role of hydroxyproline in stabilizing the triple helix of collagen. Biochem. Biophys. Res. Commun. 52:115-120.

41. Wenstrup, R. J., and P. H. Byers. 1985. Biochemical heterogeneity in mild, dominant osteogenesis imperfecta. Am. J. Hum. Genet. 37:A21. (Abstr.)

42. Toole, B. P., A. H. Kang, R. L. Trelstad, and J. Gross. 1972. Collagen heterogeneity within different growth regions of long bones of rachitic and non-rachitic chicks. Biochem. J. 127:715-720.

43. Barnes, M. J., B. J. Constable, L. F. Morton, and E. Kodicek. 1973. Bone collagen metabolism in vitamin D-deficiency. Biochem. $J$. 132:113-115. 